\title{
Voluntary ingestion of wood shavings by obese horses under dietary restriction
}

\author{
Gemma C. Curtis ${ }^{1}$, Clare F. Barfoot ${ }^{2}$, Alexandra H. A. Dugdale ${ }^{1}$, Patricia A. Harris ${ }^{2}$ \\ and Caroline McG. Argo ${ }^{1 *}$ \\ ${ }^{1}$ University of Liverpool, School of Veterinary Science, Leahurst Campus, Chester High Road, Neston, Wirral CH64 7TE, UK \\ ${ }^{2}$ Equine Studies Group, Waltham Centre for Pet Nutrition, Freeby Lane, Waltham-on-the-Wolds, Melton Mowbray, \\ Leicestershire LE14 4RT, UK
}

(Received 18 October 2010 - Revised 15 December 2010 - Accepted 11 January 2011)

\section{Abstract}

Dietary restriction for the weight-loss management of obese horses limits the natural trickle-feeding behaviour. During feed restriction, wood shavings are often advised as bedding to prevent dietary supplementation from non-feed sources. Data from twelve overweight/ obese horses and ponies of mixed breed and sex, bedded on wood shavings during 16 weeks of feed restriction, were retrospectively evaluated. DM intake (DMI) was restricted to $1.25 \%$ of body mass (BM) daily. Animals were randomly assigned to one of two diets (hay/chaff, $n$ 6; hay/balancer meal, $n$ 6). BM was recorded weekly. Feeding behaviour was recorded by continual observation over $24 \mathrm{~h}$ during week 15. The apparent digestibility (gross energy (GE), acid-detergent fibre (ADF) and DM) of feed was determined for all animals by total faecal collection $(72 \mathrm{~h}$, week 16$)$. Rates of weight loss were independent of diet type, DM $\left(R^{2} 0 \cdot 15\right)$, GE $\left(R^{2} 0 \cdot 20\right)$ and ADF digestibilities $\left(R^{2} 0 \cdot 18\right)$. Despite similar DMI, faecal DM ranged between 0.52 and $1.16 \%$ of BM daily and was associated with wide ranges in apparent digestibility (GE -11.34 to $53.08 \%$; ADF -50.37 to $42.83 \%$ and DM $2 \cdot 14$ to $57 \cdot 32 \%$ ), which were improbably low for some animals. Apparent digestibilities were associated with DM output (GE $R^{2} 0.96$; ADF $R^{2} 0.99$ and DM $R^{2} 0.99$ ) and time spent feeding (GE $R^{2} 0.62$; DM $R^{2} 0.61$ and ADF $R^{2}$ 0.59), indicating that feed intake was supplemented with wood shavings in at least five of the twelve animals. Quantities of wood shavings ingested (negligible to $>3.0 \mathrm{~kg} / \mathrm{d}$ ) were back-calculated from predicted feed digestibilities. All animals remained healthy. Implications of 'feed-bulking/energy dilution' for feed-restricted animals need further consideration.

\section{Key words: Weight loss: Feed restriction: Obesity: Appetite: Wood shavings}

The recent upsurge in the incidence of obesity among domestic horses and ponies has increased the need to provide evidence-based, corrective advice for the nutrition and management of overweight animals, for which concurrent exercise is often contraindicated ${ }^{(1,2)}$. Weight-loss management generally requires dietary restriction, which typically limits the expression of normal feeding activities and may result in the development of undesirable behaviours ${ }^{(3,4)}$.

When food intake is restricted, 'inedible' bedding materials such as wood shavings or paper are often recommended to prevent the ingestion of 'non-feed' substrates such as straw. The ingestion of large quantities of straw bedding has been identified as a risk factor for the occurrence of some impaction colics ${ }^{(5)}$
The present study retrospectively evaluated the suitability of wood shavings as a bedding material to complement the management of feed-restricted horses and ponies in a controlled weight-loss programme.

\section{Experimental methods}

A total of twelve mature (5-16 years old) horse and pony mares ( $n$ 6) and geldings ( $n$ 6) of various heights and breeds (Shetland to Warmblood), which were in overweight to obese body condition score (BCS 7.8/9 (SEM 0.24), where BCS 1 indicates emaciated and BCS 9 indicates obese ${ }^{(6,7)}$ ) at outset, were studied for 16 weeks (October-February). All animals recruited into the trial were in good clinical

Abbreviations: ADF, acid-detergent fibre; BCS, body condition score; BM, body mass; DM, dry matter; DMI, dry matter intake; FW, fresh weight; GE, gross energy.

The present study was carried out at the University of Liverpool, School of Veterinary Science, Leahurst Campus, Chester High Road, Neston, Wirral CH64 7TE, UK.

*Corresponding author: C. McG. Argo, fax +44 151794 6034, email c.m.argo@liverpool.ac.uk 
and dental health, and prophylactic anthelmintics were administered on entry. Animals were individually housed in loose boxes $(6 \mathrm{~m} \times 5 \mathrm{~m})$ bedded with wood shavings (DM 85.73\%; gross energy (GE) $23.86 \mathrm{MJ} / \mathrm{kg} \mathrm{DM}$; acid-detergent fibre (ADF) $783 \mathrm{~g} / \mathrm{kg} \mathrm{DM}$ ). Water was freely available at all times. For approximately $30 \mathrm{~min}$ each day, animals were fitted with anti-grazing muzzles (Shires, UK) and turned out in pairs to exercise at liberty in grass paddocks. Data were collected in accordance with ethical approval from the University of Liverpool.

\section{Study design}

Animals were randomly assigned to one of two equally sized groups. Food intake for all animals was restricted to $1.25 \%$ of actual body mass (BM) as DM daily, as one of two, isoenergetic, forage-based diets. Group 1 ( $n$ 6; BM 479 (SEM 222) kg, BCS 8.1/9 (SEM 0.2)) were fed grass hay (DM $84.40 \%$, GE $19.97 \mathrm{MJ} / \mathrm{kg}$ DM, ADF $431 \mathrm{~g} / \mathrm{kg} \mathrm{DM}$ ) to $1 \cdot 15 \%$ of $\mathrm{BM}$ with $0 \cdot 1 \%$ of $\mathrm{BM}$ as a nutrient balancer meal (DM 88.42\%, GE $18.76 \mathrm{MJ} / \mathrm{kg} \mathrm{DM}$, ADF $79 \mathrm{~g} / \mathrm{kg} \mathrm{DM}$, BUCKEYE $^{\circledR}$, Milton Keynes, UK). Group 2 ( $n$ 6; BM 489 (SEM 256) $\mathrm{kg}$, BCS 7.6/9 (SEM 0.2)) were fed $0.45 \% \mathrm{BM}$ as grass hay from the same batch offered to group 1 and $0.8 \%$ of $\mathrm{BM}$ as a chaff-based complete feedstuff (DM 88.14\%, GE $19.79 \mathrm{MJ} / \mathrm{kg}$ DM; ADF $387 \mathrm{~g} / \mathrm{kg} \mathrm{DM}$, fibre length $1-3 \mathrm{~cm}$; SPILLERS $^{\circledR}$, Milton Keynes, UK). Feed provision was recalculated weekly in accordance with changes in the BM of individual animals. Daily feed allowances were weighed to the nearest $10 \mathrm{~g}$ as fresh weight (FW). Hay was fed from doubled, small-mesh nets. Chaff and balancer were provided in deep, anti-spill buckets and feed bowls, respectively. Daily hay and chaff rations were equally divided and fed as two meals (08.30 and 16.00 hours). The nutrient balancer meal was dampened and offered to group 1 as a single meal (08.30 hours). All feeds were completely consumed by all animals on every occasion.

\section{Feeding behaviour}

Feeding behaviour was evaluated after 15 weeks of dietary restriction. The total daily time $(\mathrm{min} / \mathrm{d})$ that each animal spent feeding was calculated by replaying of continuous recordings collected over $24 \mathrm{~h}$ from closed-circuit television cameras erected outside each stable (RapidOS Technology Corporation, Taipei, Taiwan). For logistic reasons, four different animals were recorded each day for three consecutive days to obtain a complete dataset $(n 12)$. Cameras were positioned to ensure complete visual coverage of the entire loose box area. Feeding was recorded as taking place when the animal was considered to be actively engaged in prehending or masticating food, either from the mangers and hay nets or from the floor.

\section{Apparent digestibility}

The apparent digestibility (GE, ADF and DM) of each study diet was determined by total faecal collection over a $72 \mathrm{~h}$ period for all animals in week 16. The bedded area within the box was substantially reduced to facilitate faecal collection. Faeces were collected and cleaned of any adherent wood shavings (minimal) within $2 \mathrm{~h}$ of defecation, and faeces were pooled for each animal during each successive $24 \mathrm{~h}$ period in robust, waterproof sacks. Actual faecal output (g DM/kg BM) varied for each animal between consecutive collection days by an average of approximately $\pm 10 \%$ ( $n$ 12; 9.36 (SEm 1.44) to $-11 \cdot 11$ (SEm 1.65)\%). The total FW of daily faecal collections were recorded for each animal ( $\pm 10 \mathrm{~g}$; Weigh-Tronix, Smethwick, West Midlands, UK) before the faeces were thoroughly mixed, sampled (approximately $200 \mathrm{~g}$ ) and stored at $-20^{\circ} \mathrm{C}$ pending analyses. Fresh samples (approximately $100 \mathrm{~g}$, as fed) of the hay, chaff feed and balancer meal were similarly collected and stored on each of the $3 \mathrm{~d}$. Samples of wood shavings used as the bedding material were collected from three separate bales, pooled,

Table 1. Apparent digestibilities (Dig) of gross energy (GE Dig), DM Dig and acid-detergent fibre (ADF Dig) for the individual animals in diet group 1 (hay and balancer meal) and diet group 2 (chaff and hay)*

(Mean values and percentages)

\begin{tabular}{|c|c|c|c|c|c|c|c|}
\hline \multirow[b]{2}{*}{ Animal } & \multirow[b]{2}{*}{ Diet } & \multicolumn{2}{|c|}{ GE Dig } & \multicolumn{2}{|c|}{ DM Dig } & \multicolumn{2}{|c|}{ ADF Dig } \\
\hline & & $\%$ & Meant & $\%$ & Mean† & $\%$ & Mean† \\
\hline $3 \ddagger$ & 1 & $45 \cdot 88$ & $44 \cdot 36$ & $50 \cdot 13$ & $49 \cdot 70$ & 34.91 & 31.86 \\
\hline $12 \ddagger$ & 1 & $42 \cdot 83$ & & $49 \cdot 28$ & & 28.80 & \\
\hline 8 & 1 & $37 \cdot 32$ & & $43 \cdot 24$ & & 25.01 & \\
\hline 11 & 1 & 34.35 & & $46 \cdot 13$ & & $27 \cdot 30$ & \\
\hline 7 & 1 & $26 \cdot 52$ & & 32.99 & & 2.37 & \\
\hline 5 & 1 & $-11 \cdot 33$ & & 2.14 & & $-50 \cdot 37$ & \\
\hline $4 \ddagger$ & 2 & 53.08 & $50 \cdot 00$ & 57.32 & 53.19 & $42 \cdot 83$ & $38 \cdot 38$ \\
\hline $6 \ddagger$ & 2 & 46.92 & & 49.07 & & 33.93 & \\
\hline 9 & 2 & $40 \cdot 16$ & & 45.65 & & 28.14 & \\
\hline 1 & 2 & 29.51 & & 33.71 & & 4.64 & \\
\hline 10 & 2 & $25 \cdot 83$ & & 34.13 & & 6.04 & \\
\hline 2 & 2 & 7.04 & & 13.56 & & -33.01 & \\
\hline
\end{tabular}

* Data were collected over three successive days. Animals have been ranked within groups in descending order of apparent Dig † The mean digestibility for each of these animal pairs is provided for each dietary component evaluated.

¥ The two animals with the highest apparent Dig within each group (diet 1, animals 3 and 12; diet 2, animals 4 and 6) were assumed not to have ingested bedding. 
mixed and subsampled (approximately 100g) pending analyses.

The DM content of wood shavings, food and faecal samples was determined by oven-drying $\left(70^{\circ} \mathrm{C}\right)$ to constant mass. The dried samples were ground (particle size $<1 \mathrm{~mm}$, Moulinex Coffret 5; Moulinex, Groupe SEB, France) and mixed thoroughly. The GE of sample DM (MJ/kg DM) was determined by bomb calorimetry (E2K Combustion Calorimeter; Digital Data Systems (Private) Limited, Northcliff, South Africa). ADF contents of faecal and feed DM were assayed using standard proximate analytical techniques ${ }^{(8)}$ (Eurofins Laboratories, Wolverhampton, UK).

Statistical analyses were performed using Excel (Microsoft Office Professional Edition 2003; Microsoft Corp., Seattle, Washington, USA) and Minitab version 15.1.0 (Minitab, Inc., State College, Pennsylvania, USA).

\section{Results}

All animals remained healthy throughout the study. No stereotypic behaviours were evident, and the consumption of bedding was not apparent to regular animal carers or following the appraisal of continuous closed-circuit television recordings over $24 \mathrm{~h}$ for any animal. Rates of weight loss (range $0 \cdot 18-0.57 \%$ of $\mathrm{BM}$ recorded after the first 'adaptive' week of dietary restriction) were independent of the diet type or the apparent digestibility of DM $\left(R^{2} 0 \cdot 20\right)$ or GE $\left(R^{2} 0 \cdot 15\right)$

Despite similar DM intake (1.25\% of BM daily) for each animal, faecal DM ranged between 0.52 and $1.16 \%$ of BM daily. Empirical data evaluation indicated that faecal DM outputs, corrected for between-animal differences in BM (g DM/kgBM per d), were strongly associated with wide ranges in the apparent digestibilities of dietary GE $(-11.34$ to $\left.53.08 \%, R^{2} 0.97\right), \quad \mathrm{DM}\left(2 \cdot 14-57 \cdot 32 \%, R^{2} 0.99\right)$ and $\operatorname{ADF}\left(-50.37\right.$ to $42.83 \%, R^{2}$ 0.99; Table 1 and Fig. 1(a)). There was also a clear association between the apparent digestibility of each dietary component and the duration of each day that the individual animals were observed feeding (DM $R^{2} 0.61$; GE $R^{2} 0.62$ and ADF $R^{2} 0.59$ ). Daily time spent eating was not influenced by diet type (group 1, 32.27 (SEM 2.93)\%; group 2, 32.72 (SEM 1.94)\%). Unless stated otherwise, data are presented as means with their standard errors of the mean.

\section{Rationale and assumptions for data reinterpretation}

Apparent digestibilities of GE, DM and ADF ranged between values within predicted reference ranges ${ }^{(9)}$ and those which were clearly 'biologically improbable' (Table 1). For some animals, excretion rates for GE (group 1, animal 5) and ADF (group 1, animal 5; group 2, animal 2) exceeded known dietary inputs.

The only biologically plausible explanation was that at least half of the animals were supplementing dietary provision from an alternative, 'non-feed' source. Within the study environment, wood shavings, used as bedding, comprised the only possible source for intake supplementation. Data

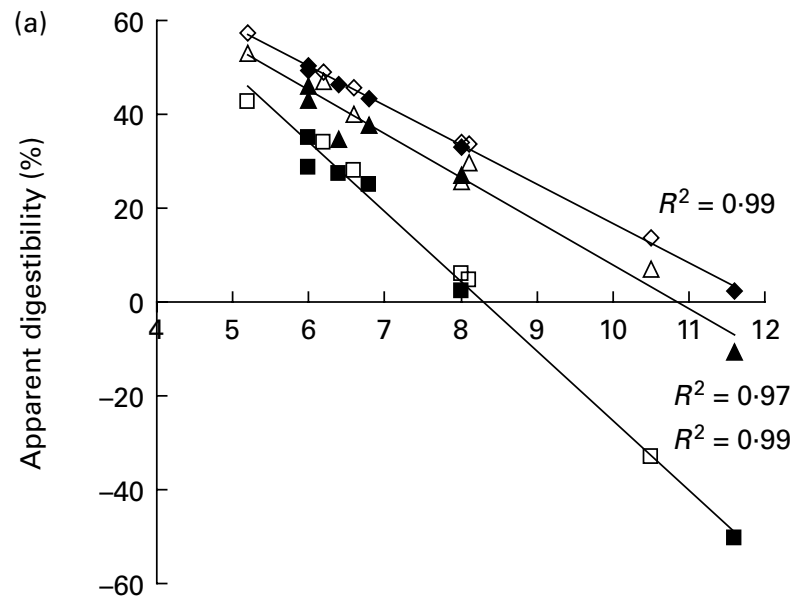

Faecal output (g/kg BM per d)

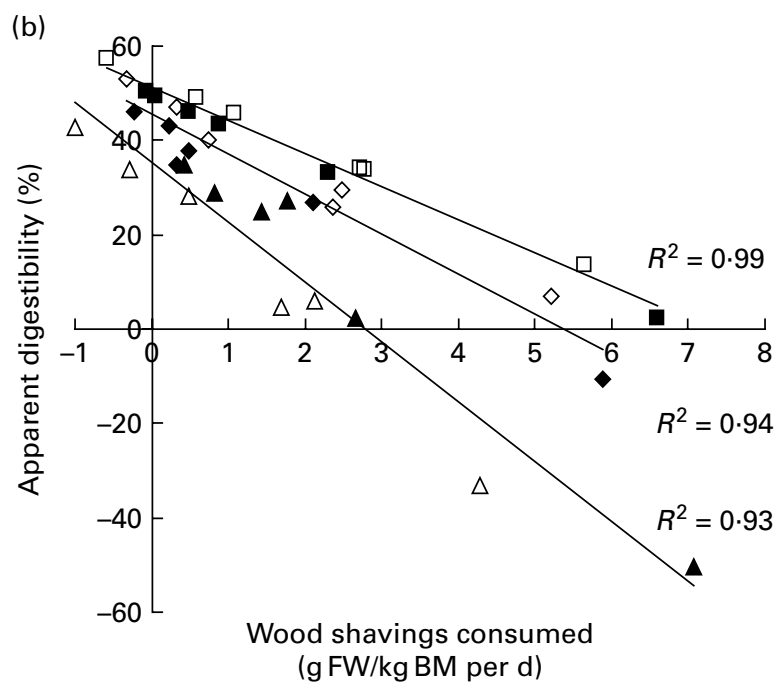

Fig. 1. Regression analysis of apparent digestibilities of gross energy (diamonds), DM (square) and acid-detergent fibre (triangles) v. (a) daily faecal DM output and (b) estimates of wood shaving consumption. Data are corrected to account for between-animal differences in body mass. The solid symbols $(\bullet, \mathbf{\square}, \mathbf{\Delta})$ depict data for diet group 1 (hay and balancer meal) and diet group 2 (chaff and hay) are represented by the open symbols $(\diamond, \square, \Delta)$. Coefficients of determination are presented for each variable. BM, body mass; FW, fresh weight.

were re-evaluated on the basis of two assumptions. First, as previously demonstrated for ruminants ${ }^{(10,11)}$, wood shavings are not digested by the equine gastrointestinal tract. It was also assumed that the two animals in each dietary group, which had the highest digestibility values for each measured variable and were within the predicted ranges for each diet, had not consumed bedding (Table 1). The mean DM, GE and ADF digestibilities for each of these horse pairs were used to calculate predicted daily faecal outputs of each component, for all animals in their respective groups, which could have been expected to result from dietary intake alone. Residual faecal DM, GE and ADF, which could not be accounted for by feedstuffs, were assumed to have originated from undigested wood shavings. The FW of wood shavings, which would have accounted for this residue, was subsequently back-calculated independently for each dietary component. 


\section{Estimated wood shaving consumption}

Estimates for quantities of wood shavings consumed by the individual animals ranged from -0.22 to $3.51 \mathrm{~kg} \mathrm{FW} / \mathrm{d}$, and when scaled for between-animal differences in BM, were strongly associated with apparent digestibility (Fig. 1(b)). Wood shaving consumption was independent of BM, diet type and individual rates of weight loss. Regression of estimates for wood shaving consumption generated independently by evaluation of data for each dietary component was clearly associated (GE on DM, $R^{2} 0.99$; DM on ADF, $R^{2}$ 0.85 and GE on ADF, $R^{2} 0.85$ ). When estimates of wood shaving consumption calculated using each component were averaged, five of the twelve animals (group 1, $n 2$; group 2, $n$ 3) were considered to have consumed over $1 \mathrm{~kg}$ of wood shavings daily (1.67 (SEM 0.07) $\mathrm{kg} \mathrm{FW/d}$ ). Estimated bedding intake by the remaining seven animals was negligible $(0 \cdot 17$ (SEM 0.09) $\mathrm{kg} \mathrm{FW} / \mathrm{d}$ ). The consumption of bedding increased the percentage of daily time spent feeding $(<1 \mathrm{kgFW}$ daily, $n$ 7, 29.2 (sеm 1.68) \%; $>1 \mathrm{~kg} \mathrm{FW}$ daily, $n$ 5, 37.11 (sEm 1.90$) \% ; P>0.005$ ).

\section{Discussion}

Almost half (five out of twelve) of the animals studied were considered to have consumed significant ( $>1 \mathrm{~kg} \mathrm{FW}$ daily) quantities of wood shavings. Food availability for these obese and overweight animals had been severely restricted to promote weight loss. The horse is a trickle feeder which, under natural conditions, may spend between 40 and $60 \%$ of grazing each day ${ }^{(12)}$. By limiting food intake and provision to two daily meals amounting to only $1.25 \%$ of $\mathrm{BM}$ as DM daily, eating, for those animals calculated to have consumed negligible amounts of bedding (seven out of twelve), occupied only $29 \cdot 2 \%$ of each day.

Although the appetite of overweight and obese animals is greatly reduced over that of non-obese counterparts, daily voluntary food intakes of obese Welsh Mountain pony mares, given ad libitum access to a diet of comparable type and quality with those used in the present study, were 2.3 (SEM $0 \cdot 2) \%$ of BM at its greatest, irrespective of season ${ }^{(13,14)}$. Appetite for ponies in that study was almost double the restricted provision offered to the present cohort of obese horses and ponies. Fed to appetite, the obese ponies of Dugdale et $_{\text {al }}{ }^{(13,14)}$ spent $45 \%$ of each day feeding. On this basis, despite the use of devices to prolong feeding activity (doubled small-gauge hay nets), it could be considered that for animals in the present study, the natural expression of feeding behaviour was reduced by $35 \%$. The consumption of bedding could be considered as a strategy to fulfil the motivational drive to feed for $45 \%$ of daily time. Wood shaving consumption by the five animals with significant intakes (five out of twelve) increased the daily time spent feeding by $8 \%$ (approximately $2 \mathrm{~h} / \mathrm{d}$ ). For one animal, estimated daily wood shaving intakes averaged $3 \cdot 24 \mathrm{~kg} \mathrm{FW}$ daily. This was associated with $44.6 \%$ of daily time spent feeding, which could be considered as complete compensation for the impact of dietary restriction on feeding time. However, many species compensate for decreased food energy density with increased appetite ${ }^{(10)}$. Interactions between 'target' feeding times and energy intakes are not fully understood for horses.

Weight-loss management for obese horses and ponies generally requires the restriction of digestible energy intake, especially where concurrent exercise may be contraindicated. The current advice would include restricting total daily feed provision to submaintenance quantities of low-energy density forages, which can be offered as several daily meals and include meal-prolonging strategies such as small-gauge hay nets ${ }^{(2,15)}$. This study suggested that animals restricted in this manner seek alternative unaccounted methods to compensate feeding time expectations. Inadvertently, this trial has offered indirect data to suggest that the motivistic drive on feeding behaviour could be protected during enforced periods of negative energy balance by energy dilution of the diet with indigestible feedstuffs. The consumption of 'less-desirable' roughages has also been observed in competition horses maintained on a high plane of nutrition and offered free access to a choice of forage types ${ }^{(16)}$. Daily wood shaving intakes for animals in the present study might be considered as minimal estimates, having been back-calculated during a digestibility trial when bedding provision had already been markedly reduced. The animals had been maintained under the same management regimen for 4 months before evaluation without ill effect. The inclusion of 'energy diluents' in the diet of horses, ponies and other domestic species has, to date, only been employed in the conduct of controlled research but warrants further investigation for the production of 'obesity diets' for 'trickle-feeding' animals ${ }^{(10,17,18)}$. Betweenanimal differences in palatability may have contributed to the breadth of the spectrum of wood shaving ingestion observed. Palatability of inert fillers has been a key determinant in the composition of feline feedstuffs ${ }^{(19,20)}$.

The advice of promoting the use of wood shavings as bedding for feed-restricted ponies may be linked to the failure of both animal carers and observers to associate 'floororientated' feeding behaviours with the ingestion of a material perceived to be 'inedible'. The present study might suggest that feed-restricted animals should be carefully observed, and where wood shaving ingestion is recognised or indicated by faecal bulking, the use of rubber matting alone should be considered.

\section{Acknowledgements}

There are no conflicts of interest. The present study was conducted within a shorter Knowledge Transfer Partnership, jointly funded by the Technology Strategy Board and MARS Horsecare UK Limited, Milton Keynes, Buckinhamshire, UK. G. C. C. was the sKTP Graduate Associate; C. McG. A., P. A. H. and C. F. B. designed the study; G. C. C. and A. H. A. D. conducted the study; C. McG. A. and G. C. C. analysed the data; C. McG. A. and G. C. C. wrote the manuscript with input from P. A. H. and C. F. B. The authors would like to express their gratitude to $\mathrm{Mr}$ Nigel Jones, Ms Georgia Moodie and Ms Hannah Carburry for their invaluable assistance in caring for the animals. 


\section{References}

1. Wyse CA, McNie KA, Tannahil VJ, et al. (2008) Prevalence of obesity in riding horses in Scotland. Vet Record 162, $590-591$

2. Dugdale AHA, Curtis GC, Harris PA, et al. (2010) Effect of dietary restriction on body condition, composition and welfare of overweight and obese pony mares. Equine Vet J 42, 600-610.

3. Cooper JJ \& Albentosa MJ (2005) Behavioural adaptation in the domestic horse: potential role of apparently abnormal responses including stereotypic behaviour. Livestock Prod Sci 92, 177-182.

4. McGreevy P, Cripps PJ, French NP, et al. (1995) Management factors associated with stereotypic and redirected behaviour in the Thoroughbred horse. Equine Vet J 27, 86-91.

5. Reeves MJ, Salman MD \& Smith G (1996) Risk factors for equine acute abdominal disease (colic): results from a multi-center case-control study. Prev Vet Med 26, 285-301.

6. Henneke DR, Potter GD, Kreider JL, et al. (1983) Relationship between condition score, physical measurements and body fat percentages in mares. Equine Vet J 15, 371-372.

7. Kohnke J (1992) Feeding and Nutrition: The Making of a Champion. Sydney, NSW: Birubi Pacific.

8. Van Soest PJ, Robertson JB \& Lewis BA (1991) Carbohydrate methodology, metabolism and nutritional implications in dairy cattle. J Dairy Sci 74, 3583-3597.

9. National Research Council (2007) Nutrient Requirements of Horses, 6th revised edition. Washington, DC: The National Academies Press.

10. Laut JE, Haupt KA, Hintz HF, et al. (1984) The effects of caloric dilution on meal patterns and food intake of ponies. Physiol Behav 35, 549-554.
11. Baumgardt BR \& Peterson AD (1971) Regulation of food intake in ruminants. 8. Caloric density of diets for young growing lambs. J Dairy Sci 54, 1191-1194.

12. Ralston SL \& Baile CA (1982) Gastrointestinal stimuli in the control of feed intake in ponies. J Anim Sci 55, 243-253.

13. Dugdale AHA, Curtis GC, Knottenbelt DC et al. (2008) Changes in body condition and fat deposition in ponies offered an ad libitum chaff-based diet. Proceedings of European Society for Veterinary Clinical Nutrition, Vienna.

14. Dugdale AHA, Curtis C, Cripps P, et al. (2011) Effect of season and body condition on appetite, body mass and body composition in ad libitum fed pony mares. Vet J (doi:10.1016/j.tvjl.2010.11.009).

15. Curtis G, Barfoot CF, Dugdale AHA, et al. (2010) Further dietary restriction is required to achieve weight loss in resistant horses. Proceedings of Waltham International Nutrient Science Symposium, Cambridge 16-18 September $\mathrm{P} 73$.

16. Goodwin D, Davidson HPB \& Harris PA (2002) Foraging enrichment for stabled horses: effects on behaviour and selection. Equine Vet J 34, 686-691.

17. Hansen BC, Jen K-LC \& Kribbs P (1981) Regulation of food intake in monkeys: response to caloric dilution. Physiol Behav 26, 479-486.

18. Ammann AP, Cowan RL, Mothershead CL, et al. (1973) Dry matter and energy intake in relation to digestibility in white-tailed deer. J Wildlife Manage 37, 195-201.

19. Castonguay TW (1981) Dietary dilution and intake in the cat. Physiol Behav 27, 547-549.

20. Kanarek RB (1975) Availability and caloric density of the diet as determinants of meal patterns in cats. Phvsiol Behav 15, 611-618. 